\title{
Estudio cinético de la hidrólisis del almidón de Solanum tuberosum, Ipomoea batatas y Manihot esculenta con amilasa termoestable de Bacillus licheniformis BA-3 aislada de los géiseres de Candarave- Tacna
}

\author{
Kinetic study of starch hydrolysis of Solanum tuberosum, Ipomoea batatas and \\ Manihot esculenta by thermoestable amylase of Bacillus licheniformis BA-3 \\ isolated from Candarave Geysers in Tacna
}

\author{
${ }^{1}$ Ariadna Zúñiga Llanos \\ ${ }^{2}$ Cristina Ferrer Villena \\ ${ }^{3}$ Israel Salazar Quispe
}

\author{
${ }^{4}$ Ana Naquiche Calero \\ ${ }^{5}$ Roberto Castellanos Cabrera
}

\section{RESUMEN}

Para la investigación, los almidones de papa (Solanum tuberosum), camote (lpomoea batatas) y yuca (Manihot esculenta) fueron hidrolizados por la enzima amilasa obtenida por cultivo líquido de la bacteria termófila, designada como Bacillus licheniformis BA-3 y aislada de los géiseres de Calientes, Candarave, Tacna. Se obtuvo el extracto crudo, el cual fue filtrado, centrifugado y precipitado con sulfato de amonio al $60 \%$ y dializado por 24 horas en refrigeración a $5{ }^{\circ} \mathrm{C}$. Asimismo, la bacteria termófila utilizada presentó el $99 \%$ de identidad mediante la secuenciación del gen $\mathrm{ARNr}$ 16S. Se evaluó la concentración de azúcares reductores de los almidones y, a partir de ello, se determinó la cinética de velocidad enzimática propuesta por Michaelis-Menten, a concentraciones de $1 \%, 1.5 \%, 2 \%, 2.5 \%$ y $3 \%$ de solución de cada almidón con $5 \mu \mathrm{l}$ de enzima amilasa a temperatura de $50{ }^{\circ} \mathrm{C} \mathrm{y} \mathrm{pH} \mathrm{7.} \mathrm{Se} \mathrm{obtuvieron} \mathrm{las} \mathrm{constantes} \mathrm{de} \mathrm{Michaelis-}$ Menten $(\mathrm{Km})$ de $0.4225 \mathrm{~g} / \mathrm{ml}, 0.0024 \mathrm{~g} / \mathrm{ml}$ y $0.1263 \mathrm{~g} / \mathrm{ml}$ para Solanum tuberosum, lpomoea batatas y Manihot esculenta, respectivamente. De igual forma, se obtuvo valores de velocidad máxima (Vmax) de $0.00091 \mathrm{~g} / \mathrm{ml} * \mathrm{~min}$, $0.00011 \mathrm{~g} / \mathrm{ml}^{*} \min$ y $0.00099 \mathrm{~g} / \mathrm{ml}$ *min para cada almidón estudiado. Se concluyó que existe mayor afinidad de la enzima producida por Bacillus licheniformis BA-3 con el almidón de lpomoea batatas por ser el menor valor de Km obtenido.

Palabras clave: Almidón, $\alpha$-amilasa, Bacillus licheniformis, cinética de velocidad enzimática.

\section{ABSTRACT}

The potato (Solanum tuberosum), sweet potato (lpomoea batatas) and yucca (Manihot esculenta) starches were hydrolyzed by the amylase enzyme obtained by liquid culture of the thermophilic bacteria designated as Bacillus Licheniformis BA-3. They were also isolated from the Calientes geysers of Candarave province in the Tacna Region. The crude extract was obtained, which was filtered, centrifuged and precipitated with $60 \%$ ammonium sulphate and dialyzed for 24 hours under refrigeration at $-5{ }^{\circ} \mathrm{C}$. Likewise, the thermophilic bacteria used showed $99 \%$ identity by sequencing the $16 \mathrm{~S}$ rRNA gene. The concentration of starch reducing sugars was evaluated and, based on this, the enzyme speed kinetics proposed by Michaelis-Menten was determined at concentrations of $1 \%, 1.5 \%, 2 \%, 2.5 \%$ and $3 \%$ solution of each starch with $5 \mu \mathrm{l}$ of amylase enzyme at a temperature of $50{ }^{\circ} \mathrm{C}$ and $\mathrm{pH}$ 7. The Michaelis-Menten's constants $(\mathrm{Km})$ of $0.4225 \mathrm{~g} / \mathrm{ml}, 0.0024 \mathrm{~g} / \mathrm{ml}$ and $0.1293 \mathrm{~g} / \mathrm{ml}$, for Solanum tuberosum, lpomoea batatas and Manihot esculenta respectively. Similarly, maximum speed values were obtained (Vmax) of $0.00091 \mathrm{~g} / \mathrm{ml} * \min , 0.00011 \mathrm{~g} / \mathrm{ml}^{*} \mathrm{~min}$ and $0.00099 \mathrm{~g} / \mathrm{ml}^{*}$ min for each starch studied, for all of which it is concluded that there was a greater affinity of the enzyme produced by Bacillus licheniformis BA-3 with the starch of lpomoea batatas since it is the lowest value of Km obtained.

Keywords: kinetics of enzymatic rate, $\alpha$-amylase, starch, Bacillus licheniformis.

Laboratorio de Investigación Biotecnología Enzimática de la Facultad de Ciencias. Universidad Nacional Jorge Basadre Grohmann, Tacna-Perú. E-mail: ariadnazunigallanos@gmail.com 'Laboratorio de Investigación Biotecnología Enzimática de la Facultad de Ciencias. Universidad Nacional Jorge Basadre Grohmann. Tacna-Perú. E-mail: ferrercristina06@gmail.com ${ }^{3}$ Laboratorio de Investigación Biotecnología Enzimática de la Facultad de Ciencias. Universidad Nacional Jorge Basadre Grohmann. Tacna-Perú. E-mail: josep12864@gmail.com ¿Laboratorio de Investigación Biotecnología Enzimática de la Facultad de Ciencias. Universidad Nacional Jorge Basadre Grohmann. Tacna-Perú. E-mail: julycalero7@gmail.com Laboratorio de Investigación Biotecnología Enzimática de la Facultad de Ciencias. Universidad Nacional Jorge Basadre Grohmann. Tacna-Perú. E-mail: robertocastellanoscabrera@yahoo.es 


\section{INTRODUCCIÓN}

La investigación se realizó para conocer la cinética enzimática de la enzima alfa-amilasa de Bacillus licheniformis BA-3, bacteria termófila encontrada en los géiseres de CalientesCandarave (Tacna-Perú), sobre sustratos alimenticios como el almidón de los tubérculos papa (Solanum tuberosum) y yuca (Manihot esculenta), y la raíz camote (Ipomoea batatas).

Anteriormente a este estudio, se desconocía la cinética enzimática de una enzima termoestable como lo es la alfa-amilasa; es decir, juntar una enzima nativa y termófila con sustratos (almidones) procedentes de especies autóctonas del Perú, como lo son la papa, el camote y la yuca. Por ello, para esta investigación se determinará la afinidad y la velocidad de reacción de la alfaamilasa sobre los sustratos ya mencionados.

La mayoría de las enzimas industriales, actualmente utilizadas, pertenecen al grupo hidrolasa, activos en muchos sustratos naturales. Los hidrolizados enzimáticos surgen de la necesidad de sustituir ciertas materias primas para ofrecer productos de gran competitividad que generen diversas opciones en el mercado. Entre algunas de sus aplicaciones están los jarabes con azúcares de mayor poder de disolución, sustancias en la preparación de color de caramelo que aportan resistencia a la decoloración térmica, dan cuerpo y acentúan los sabores a frutas y mejoran el color y las texturas. Serían algunas de las razones por las cuales cobran importancia hoy en día (Pardo, Rivera, Castellano y González, 2004).

Los microorganismos son la principal fuente de muchas enzimas, identificados después de una extensa investigación y que en la actualidad tienen uso en aplicaciones industriales (Burhan, Nisa, Gokhan, Omer, Ashabil \& Osman, 2003). Las amilasas se pueden obtener de varias fuentes (Van der Maarel, Van der Veen, Uitdehaag, Leemhuis, \& Dijkhuizen, 2002; Aquino, Jorge, Terenzi \& Polizeli, 2003) y el género más conocido que secreta esta enzima son las especies de Bacillus. La amilasa es la enzima encargada principalmente de degradar el almidón y convertirlo en dextrina.

Las amilasas son enzimas importantes utilizadas en la industria y representan aproximadamente el $25 \%$ del mercado de enzima (Sidhu, Sharma, Chakrabarti \& Gupta, 1997), ya que tienen aplicaciones comerciales extensas en el procesamiento de almidón, elaboración de la cerveza y la producción de azúcar, desencolado en la industria textil y en los procesos de fabricación de detergentes (Hendriksen, Pedersen \& BisgardFrantzen, 1999; Lévêque, Janecek, Haye, \& Belarbi, 2000).

El objetivo del presente trabajo fue determinar la afinidad de la enzima de la bacteria termófila BA3 Bacillus licheniformis por los almidones de papa (Solanum tuberosum), yuca (Manihot esculenta) y camote (lpomoea batatas).

\section{MATERIAL YMÉTODOS}

\section{Obtención de materia prima}

Las materias primas empleadas fueron Solanum tuberosum, lpomoea batatas y Manihot esculenta, obtenidas por selección aleatoria en puestos de verduras del mercado mayorista Grau del departamento de Tacna. Se tuvo como carácter de exclusión: presencia de tejido necrótico y daños. No se consideró el tamaño como factor de exclusión.

\section{Obtención del almidón}

La extracción se realizó utilizando el método Carver (Carver, 1937). Para lo cual, se procedió a lavar el sustrato con agua; asimismo se retiró la epidermis para el rallado, lo que permitió liberar los gránulos de almidón contenidos en las células del parénquima que fueron tamizados en un lienzo de nylon, permitiendo solo el paso de líquido. La sedimentación del almidón en medio líquido se realizó en matraces de $500 \mathrm{ml}$ por 24 horas, se retiró el agua sobrenadante y rastros de impurezas en la superficie. Luego, el almidón se resuspendió en agua con el objetivo de eliminar la mayor cantidad de impurezas (4-5 horas). El secado del almidón se realizó en estufa por 24 horas.

Además, se midió el rendimiento de extracción de almidón, el cual se expresó en gramos del almidón extraído/Kilogramos de sustrato fresco.

\section{Caracterización físico-química del almidón}

El análisis físico químico se realizó empleando la metodología de la AOAC (1990) para la determinación del porcentaje de humedad, cenizas, proteínas y fibra bruta. Las muestras se analizaron por triplicado. 
Características de la enzima amilasa obtenida de Bacillus licheniformis aislada de géiseres de Calientes, Candarave-Tacna

Se utilizó la enzima amilasa proporcionada por el Laboratorio de Bioquímica y Nutrición de la Universidad Nacional Jorge Basadre Grohmann, obtenida de Bacillus licheniformis BA-3, aislada de los géiseres de Calientes-Candarave; la misma que cataliza la hidrólisis de enlaces glucosídicos ramificados, purificada en sulfato de amonio $\left[\mathrm{SO}_{4}\left(\mathrm{NH}_{4}\right)_{2}\right]$ al $60 \%$. Esta enzima presenta una temperatura óptima de $50^{\circ} \mathrm{Cy} \mathrm{pH} 7$.

\section{Hidrólisis enzimática del almidón}

El procedimiento experimental se realizó utilizando la metodología de Salcedo, Montes, \& Zapata (2010). Para lo cual se utilizó $5 \mathrm{ml}$ de solución de almidón en concentraciones de $1 \%$, $1.5 \%, 2 \%, 2.5 \%$ y $3 \%$ p/v, a pH 7 y se agregó $5 \mu 1$ de la enzima amilasa de Bacillus licheniformis BA-3, purificada en sulfato de amonio al $60 \%$.

Se incubó a $50{ }^{\circ} \mathrm{C}$ por una hora, tomándose muestras cada 10 minutos. El seguimiento de la velocidad de la hidrólisis enzimática fue controlado por medio de la determinación de azúcares reductores producidos a diferentes tiempos. Para ello, se utilizó DNS (ácido 3-5dinitrosalicílico). Se empleó glucosa anhidra para la elaboración de la curva patrón. La lectura de la absorbancia fue a $540 \mathrm{~nm}$ de longitud de onda en espectrofotómetro.

\section{Análisis estadístico}

Se realizó un diseño unifactorial de las combinaciones de las concentraciones de almidón y la concentración de azúcares reductores mediante MINITAB 18, realizando un ANOVA $(\alpha=0.05)$ de las medias de la relación $\mathrm{DH} / \mathrm{DC}$ y seleccionando la prueba de Tukey $(\alpha=0.05)$ para identificar la media significativamente más alta.

Se graficaron proyecciones de la cinética de Michaelis-Menten y Linweaver-Burk para determinación de las constantes cinéticas Vmax y $\mathrm{Km}$, respectivamente.

Velocidad inicial de reacción $\left(\mathrm{v}_{0}\right)$, constante de Michaelis-Menten $(\mathrm{Km})$ y velocidad máxima de reacción(Vmax)

De la curva de concentración de glucosa en función del tiempo se obtuvo los datos de $\mathrm{v}_{0}$ para cada una de las concentraciones de sustrato inicial
$\left(\mathrm{S}_{0}\right)$ conocidas. Para ello, se realizó la medida de la $\mathrm{V}_{0}$ cuando la reacción enzimática estaba en el estado de saturación, donde los centros activos de la enzima se encuentran llenos de sustrato. Para evitar el error introducido por el deterioro de la enzima, el cálculo de la $\mathrm{v}_{0}$ se realizó antes que se consumiera el $10 \%$ de sustrato que es la pendiente de la curva de avance a un tiempo menos de 30 minutos. Como la dosificación de enzima es muy pequeña y la $S_{0}$ es muy grande al comienzo de la reacción se considera que la concentración de enzima-sustrato es constante para toda la reacción. Siguiendo la cinética de velocidad propuesta por Michaelis-Menten, de los datos de $\mathrm{v}_{0}$ y $\mathrm{S}_{0}$ obtenidos a concentraciones de $1 \%, 1.5$ $\%, 2 \%, 2.5 \%$ y $3 \% \mathrm{p} / \mathrm{v}$ de los almidones estudiados con dosificaciones de enzima constante de $5 \mu 1$ concentrado con sulfato de amonio $\left[\mathrm{SO}_{4}\left(\mathrm{NH}_{4}\right)_{2}\right]$ al $60 \%$. Se calcularon los valores de Km y Vmax.

\section{RESULTADOS}

\section{Obtención de almidón}

En el proceso de extracción del almidón se obtuvo, a partir de $500 \mathrm{~g}$ de sustrato, un promedio de $147.5 \mathrm{~g}$ de almidón de Manihot esculenta, $418.04 \mathrm{~g}$ de almidón de Solanum tuberosum y $106.09 \mathrm{~g}$ de almidón de lpomoea batatas; con un rendimiento para Solanum tuberosum, Manihot esculenta e lpomoea batatas del $32.73 \%, 29.50 \%$ y $21.66 \%$ respectivamente. Siendo el sustrato de elección Solanum tuberosum por tener un rendimiento del $32.73 \%$ en la obtención de almidón (Tabla 1).

Tabla 1. Resultados de rendimiento de producción de almidón por cada 500 gramos de sustrato

\begin{tabular}{ccccc} 
SUSTRATo & $\begin{array}{c}\text { Almidón } \\
\text { (g) }\end{array}$ & $\begin{array}{c}\text { Cáscara } \\
(\mathbf{g})\end{array}$ & $\begin{array}{c}\text { Pulpa Rendimiento } \\
(\mathrm{g})\end{array}$ & $\mathbf{( \% )}$ \\
$\begin{array}{c}\text { Manihot } \\
\text { esculenta }\end{array}$ & 147.5 & 37.5 & 462.5 & 29.50 \\
$\begin{array}{c}\text { Solanum } \\
\text { tuberosum } \\
\text { lpomoea } \\
\text { batatas }\end{array}$ & 163.67 & 80.95 & 419.05 & 32.73 \\
\hline & 106.09 & 50.00 & 450 & 21.66 \\
\hline
\end{tabular}

\section{Caracterización fisicoquímica de los sustratos de almidón}

Los resultados de la caracterización bromatológica correspondiente a humedad, proteína, grasa ceniza y fibra se encuentran por 
encima de los parámetros establecidos por el Instituto de Investigación Tecnológica Industrial y de Normas Técnicas (ITINTEC, 1986) (Tabla 2).

Tabla 2. Resultados de la caracterización fisicoquímica de los sustratos de almidón

\begin{tabular}{lccc|}
$\begin{array}{c}\text { Variables } \\
(\%)\end{array}$ & $\begin{array}{c}\text { Solanum } \\
\text { tuberosum }\end{array}$ & $\begin{array}{c}\text { Sustratos } \\
\text { lpomoea } \\
\text { batatas }\end{array}$ & $\begin{array}{c}\text { Manihot } \\
\text { esculenta }\end{array}$ \\
\hline Humedad & 17.2 & 16.5 & 15.5 \\
Proteína & 1.850 & 1.16 & 0.729 \\
Grasa & 0.028 & 0.056 & 0.103 \\
Ceniza & 1.092 & 0.703 & 0.740 \\
Fibra & 0.500 & 0.819 & 1.028 \\
\hline
\end{tabular}

\section{Determinación de la concentración de} azúcares reductores

Tabla 3. Análisis de varianza de los factores evaluados para la producción de azúcares reductores por enzima amilasa de la bacteria termófila Bacillus licheniformis BA-3 aislada de los géiseres de Calientes, CandaraveTacna

\begin{tabular}{|c|c|c|c|c|c|}
\hline Fuente & $\begin{array}{l}\text { Suma de } \\
\text { Cuadrados }\end{array}$ & $g l$ & $\begin{array}{l}\text { Cuadrado } \\
\text { Medio }\end{array}$ & Razón-F & Valor-P \\
\hline \multicolumn{6}{|c|}{ EFECTOS PRINCIPALES } \\
\hline A : sustrato & $2.32505 \mathrm{E} 8$ & 2 & $1.16253 \mathrm{E} 8$ & 103.54 & 0.0000 \\
\hline B : tiempo & $9.60776 \mathrm{E} 7$ & 5 & $1.92155 \mathrm{E} 7$ & 17.11 & 0.0000 \\
\hline $\begin{array}{c}\text { C : concentración } \\
\text { de sustrato }\end{array}$ & $4.68665 \mathrm{E} 7$ & 4 & $1.17166 \mathrm{E} 7$ & 10.44 & 0.0000 \\
\hline RESIDUOS & $8.75738 \mathrm{E} 7$ & 78 & $1.12274 \mathrm{E} 6$ & & \\
\hline TOTAL (CORREGIDO) & 4.63023E8 & 89 & & & \\
\hline
\end{tabular}

La Tabla 3 muestra la interacción de los efectores evaluados: tiempo (min), concentración de almidón $(\mathrm{mg} / \mathrm{ml})$ y procedencia del almidón (papa: Solanum tuberosum, yuca: Manihot esculenta y camote: lpomoea batatas). Los cuales resultaron ser significativos sobre la producción de azúcares reductores.

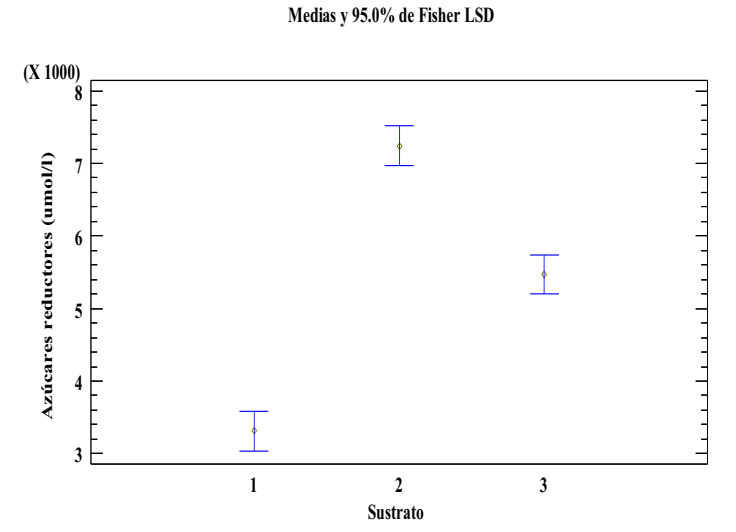

Figura 1. Concentración de azúcares reductores obtenida de la hidrólisis del almidón de Solanum tuberosum (1), Manihot esculenta (2) e lpomoea batatas (3), con la enzima amilasa de la bacteria termófila Bacillus licheniformis BA-3 aislada de los géiseres de Calientes, Candarave-Tacna. Fuente: Statgraphics Centurion

La Figura 1 muestra que la mayor producción de azúcares reductores (umol/1) se dio con el hidrólisis del almidón de Manihot esculenta.

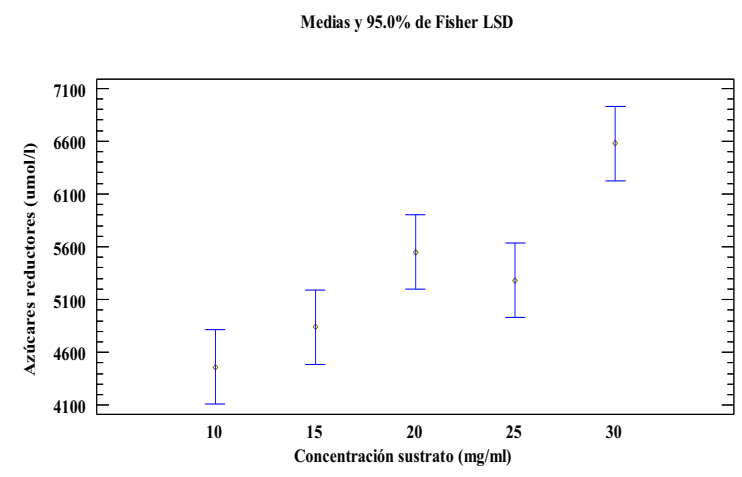

Figura 2. Concentración de azúcares reductores obtenidos de la hidrólisis a concentraciones de almidón de Solanum tuberosum, Manihot esculenta e lpomoea batatas, con la enzima amilasa de la bacteria termófila Bacillus licheniformis BA-3, aislada de los géiseres de Calientes, Candarave-Tacna.

Fuente: Statgraphics Centurion.

La Figura 2 muestra que la mayor producción de azúcares reductores (umol/l) durante la hidrólisis del almidón de Solanum tuberosum, Manihot esculenta e lpomoea batatas se dio en la mayor concentración de almidón $30(\mathrm{mg} / \mathrm{ml})$. 


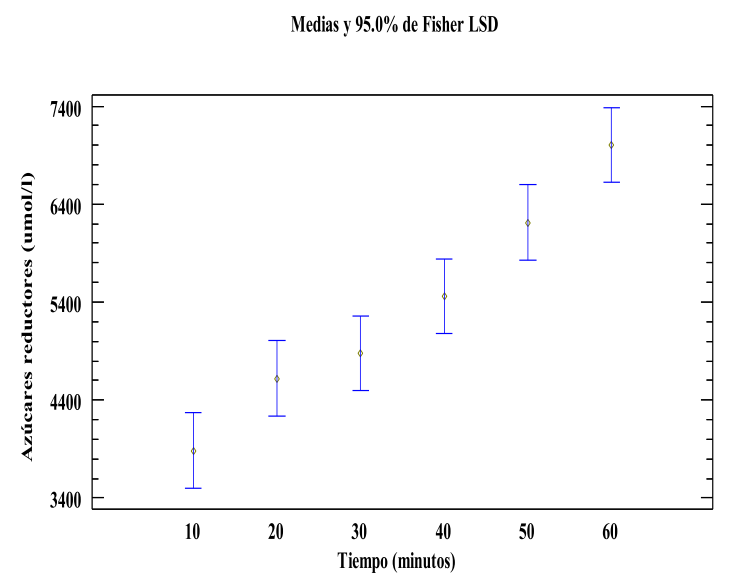

Figura 3. Concentración de azúcares reductores obtenidos de la hidrólisis a diferentes tiempos de incubación de Solanum tuberosum, Manihot esculenta e lpomoea batatas con la enzima amilasa de la bacteria termófila Bacillus licheniformis BA-3 aislada de los géiseres de Calientes, Candarave-Tacna.

Fuente: Statgraphics Centurion

La Figura 3 muestra que la mayor producción de azúcares reductores (umol/l) durante la hidrólisis del almidón de Solanum tuberosum, Manihot esculenta e lpomoea batatas se dio a 60 minutos de incubación.

Cálculo de la $\mathrm{v}_{0}$ de la reacción enzimática $\mathrm{y}$ valores de $\mathrm{Km}$ y Vmax de los diferentes sustratos de almidón

Considerando el recorrido efectuado, es importante resaltar que el estudio cinético realizado es confiable desde el punto de vista experimental y que los resultados arrojados son fundamentales para tener parámetros claves que permitirán realizar un modelamiento teórico. Los datos para la realización de la cinética se reportaron con base en la cantidad de azúcares reductores formados.

Se planearon cinco ensayos con las condiciones de reacción optimizadas preliminarmente; temperatura de $50{ }^{\circ} \mathrm{C}$ y $5 \mu$ enzima amilasa por cada 5 mililitros de solución de almidón de los diferentes sustratos de almidón. Las concentraciones de sustrato iniciales por probar fueron de $1 \%, 1,5 \%, 2 \%, 2,5 \%$ y $3 \% \mathrm{p} / \mathrm{v}$.

Para cada cinética de tiempo se halló la velocidad inicial de reacción designada por $\mathrm{v}_{0}$, la cual es la pendiente de la curva de avance de la reacción al tiempo cero. Posteriormente, graficando $\mathrm{v}_{0}$ contra la concentración inicial de sustrato $\left(\mathrm{S}_{0}\right)$, se obtuvo la cinética de reacción de Michaelis Menten. Los parámetros cinéticos $\mathrm{km}$ y Vmax se hallaron mediante regresión lineal de Linewever-Burk.
Tabla 4. Cálculo de la velocidad inicial a diferentes concentraciones de sustrato de almidones obtenidos

$\begin{array}{lccc}\text { [S] g/ml } & \text { v1 } & \text { v2 } & \text { v3 } \\ & & \mathrm{mg} / \mathrm{ml}^{*} \min \\ \\ 0.010 & 0.00002134 & 0.0000764 & 0.0000858 \\ 0.015 & 0.00002997 & 0.0000995 & 0.0000920 \\ 0.020 & 0.00003981 & 0.0001231 & 0.0000955 \\ 0.025 & 0.00005494 & 0.0001452 & 0.0000978 \\ 0.030 & 0.00005996 & 0.0001769 & 0.0000980\end{array}$

Donde:

v1: Solanum tuberosum, v2: Manihot esculenta, v3: lpomoea batatas

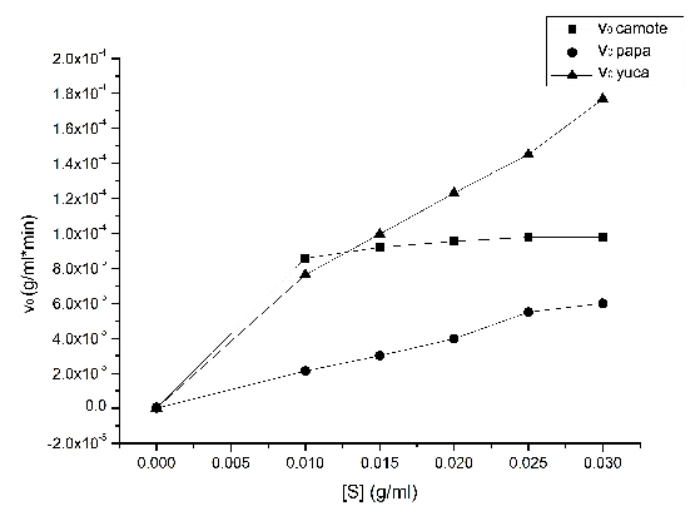

Figura 4. Curva potencial de $\mathrm{v}_{0}$ versus [S]

La Figura 4 describe la velocidad inicial de reacción de la enzima amilasa de la bacteria termófila Bacillus licheniformis BA-3 frente a los diferentes sustratos de almidón.

Tabla 4. Parámetros inversos de sustrato y velocidades iniciales

\begin{tabular}{|c|c|c|c|}
\hline 1/S (g/ml) & $1 / v_{1}$ & $\begin{array}{l}1 / \mathrm{v}_{2} \\
\left(\mathrm{~g} / \mathrm{ml}{ }^{*} \mathrm{~min}\right)\end{array}$ & $1 / v_{3}$ \\
\hline 100.0 & 13089.0 & 11655,01 & 46860,36 \\
\hline 66.7 & 10050,25 & 10869,56 & 33366,70 \\
\hline 50.0 & 8123,48 & 10471,20 & 25119,32 \\
\hline 40.0 & 6887,05 & 10224,95 & 18201,67 \\
\hline 33.3 & 5652,91 & 10204,08 & 16677,79 \\
\hline
\end{tabular}

Donde:

$\mathrm{v}_{1}$ : Solanum tuberosum, $\mathrm{v}_{2}$ : Manihot esculenta, $\mathrm{v}_{3}$ : lpomoea batatas 


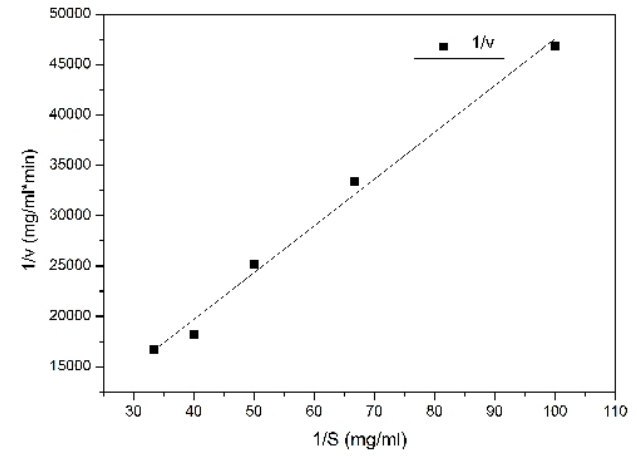

\begin{tabular}{|c|c|c|c|}
\hline Ecuation & \multicolumn{3}{|l|}{$y=a+b * x$} \\
\hline Adj. R -Square & \multicolumn{3}{|l|}{0.98921} \\
\hline & Value & & \\
\hline $1 / \mathrm{v}$ & Intercept & 1099.51466 & 1518.6834 \\
\hline $1 / \mathrm{v}$ & Slope & 464.5802 & 24.22198 \\
\hline
\end{tabular}

$* \mathrm{Km}=0.4225 \mathrm{~g} / \mathrm{ml}, \mathrm{Vmax}=0.00091 \mathrm{~g} / \mathrm{ml} * \min$

* Condiciones de reacción: Temperatura $50{ }^{\circ} \mathrm{C}, \mathrm{pH} 7$ y $5 \mu \mathrm{lde}$ enzima purificada en sulfato de amonio $\left[\mathrm{SO}_{4}\left(\mathrm{NH}_{4}\right)_{2}\right]$ al $60 \%$

Figura 5. Representación de la ecuación de Lineweaver-Burk para el almidón de papa (Solanum tuberosum)

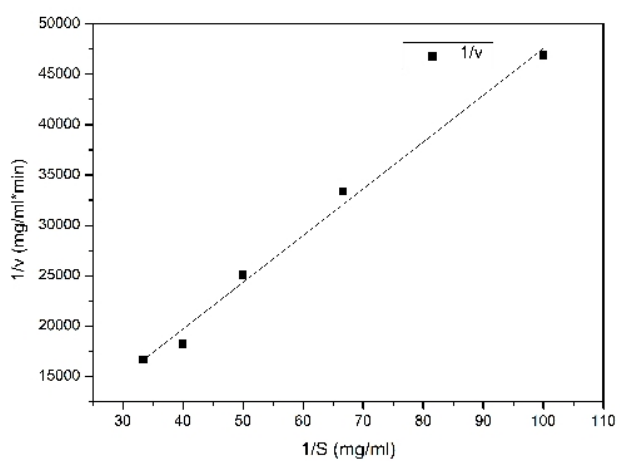

\begin{tabular}{llll}
\hline Ecuation & $\mathrm{y}=\mathrm{a}+\mathrm{b}^{*} \mathrm{x}$ & \multicolumn{2}{c}{ Standard Error } \\
\hline Adj. R -Square & 0.9625 & \multicolumn{2}{c}{653.2231} \\
\hline \multicolumn{1}{l}{} & Value & 1027.2503 & 11.41286 \\
\hline $1 / \mathrm{v}$ & Intercept & 129.79033 & \\
$1 / \mathrm{v}$ & Slope & &
\end{tabular}

$* \mathrm{Km}=0.1263 \mathrm{~g} / \mathrm{ml}, \mathrm{Vmax}=0.00099 \mathrm{~g} / \mathrm{ml} * \min$ *Condiciones de reacción: Temperatura $50{ }^{\circ} \mathrm{C}, \mathrm{pH} 7 \mathrm{y}$ dosis enzimática de $5 \mu$ purificada en sulfato de amonio $\left[\mathrm{SO}_{4}\left(\mathrm{NH}_{4}\right)_{2}\right]$ al $60 \%$

Figura 6. Representación de la ecuación de Lineweaver Burk para el almidón de yuca (Manihot esculenta)

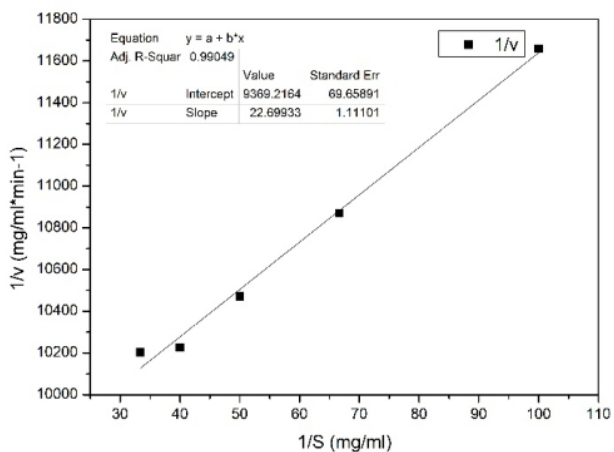

\begin{tabular}{llrr}
\hline Ecuation & $\mathrm{y}=\mathrm{a}+\mathrm{b} * \mathrm{x}$ & \multicolumn{3}{c}{} \\
\hline Adj. R -Square & 0.99049 & \multicolumn{2}{c}{ Standard Error } \\
\hline & & Value & 96.65891 \\
$1 / \mathrm{v}$ & Intercept & 9369.2164 & 1.11101 \\
\hline $1 / \mathrm{v}$ & Slope & 22.69933 & \\
\hline
\end{tabular}

$* \mathrm{Km}=0.0024 \mathrm{~g} / \mathrm{ml}, \mathrm{Vmax}=0.00011 \mathrm{~g} / \mathrm{ml} * \min$

* Condiciones de reacción: Temperatura $50{ }^{\circ} \mathrm{C}, \mathrm{pH} 7$ y dosis enzimática de $5 \mu$ purificada en sulfato de amonio $\left[\mathrm{SO}_{4}\left(\mathrm{NH}_{4}\right)_{2}\right]$ al $60 \%$

Figura 7. Representación de la ecuación de Lineweaver Burk para el almidón de camote (lpomoea batatas)

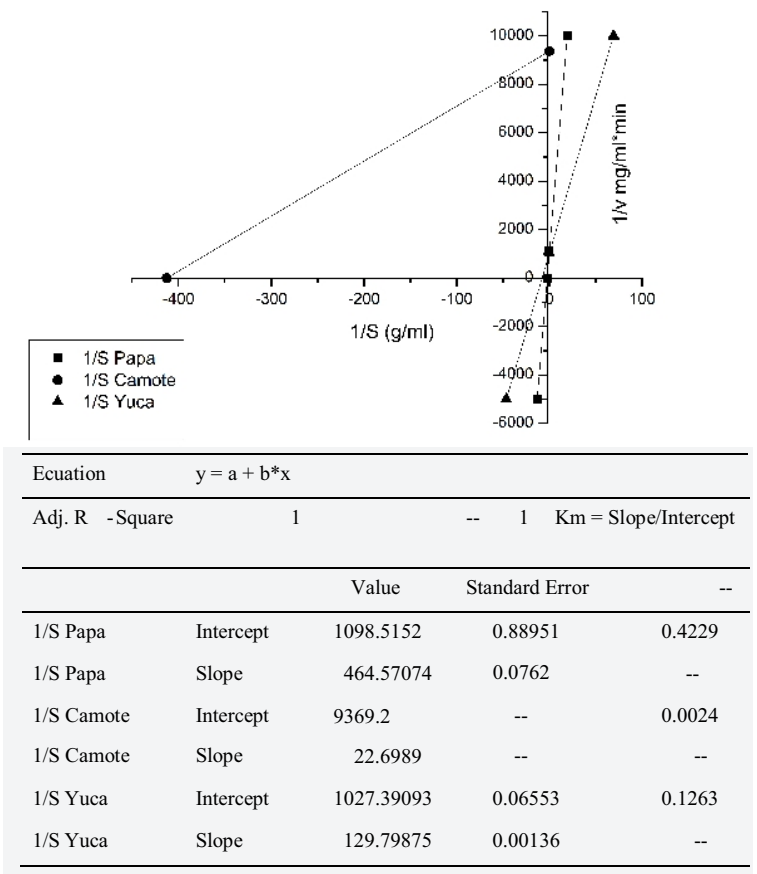

Figura 8. Representación de la ecuación de Lineweaver Burk para el almidón de papa (Solanum tuberosum), yuca (Manihot esculenta) y camote (lpomoea batatas)

Las figuras 5, 6, 7 y 8 muestran que mediante la ecuación de Lineweaver-Burk se pudo calcular los valores de $\mathrm{Km}$ y Vmax, y de esta forma determinar la afinidad de la enzima amilasa de la bacteria termófila Bacillus licheniformis BA-3 aislada de los géiseres de Calientes, CandaraveTacna.

\section{DISCUSIÓN}

\section{Obtención de almidón}

En la Tabla 1 se puede observar que hay diferencia entre el porcentaje de rendimiento de almidón de los tres tubérculos. El mayor rendimiento fue de 
$32.73 \%$ para Solanum tuberosum, seguido de Manihot esculenta con $29.50 \%$, mientras que el menor rendimiento fue de $21.66 \%$ para la variedad lpomoea batatas. Cabe destacar que estos valores superan al porcentaje de fuentes importantes de almidón como la papa, camote, yuca y maíz (7-18 \%), según Arzapalo, Huamán, Quispe y Espinoza (2015). Esta diferencia, comparada con los resultados obtenidos, se debe a las variedades en estudio y a las condiciones climatológicas en las que se desarrollan. Ello está corroborado por Singh, Singh, Kaur, Sodhi \& Gill (2003), quienes señalan que la relación amilosa/amilopectina en los almidones varía de acuerdo al origen botánico, al clima y tipo de suelo, al proceso de obtención y purificación, así como las condiciones de almacenamiento.

\section{Caracterización físico-química de los sustratos de almidón}

El contenido de humedad en los gránulos de almidón de tubérculos de varias raíces va de 14 a $19 \%$. Para las grasas, concuerda con autores como Guizar (2009), quien menciona que las grasas en almidones de tubérculos como Solanum tuberosum, Manihot esculenta e lpomoea batatas es muy bajo $(<0.1 \%)$.

Para la fibra, Raygada (2001), en su investigación, determinó valores inferiores comparados a los nuestros. Estos son $0.500 \%$, $1.028 \%$ y $0.819 \%$ para almidón de Solanum tuberosum, Manihot esculenta e lpomoea batatas, respectivamente.

El contenido de proteína de los almidones evaluados mostró índices altos de proteína con $1.850 \%, 0.729 \%$ y 1,16 \% para Solanum tuberosum, Manihot esculenta e lpomoea batatas; encontrándose fuera del nivel permitido por el Instituto de Investigación Tecnológica Industrial y de Normas Técnicas (ITINTEC). Esta diferencia, probablemente, se debe a las variedades en estudio y a las condiciones en las que se desarrolló la extracción. Por lo tanto, esto hace que la utilización de estos almidones en la producción de jarabes con alta calidad de contenido de glucosa no sea factible, ya que en el proceso podrían producirse reacciones desfavorables (Zajac, 1989).

\section{Determinación de azúcares reductores}

En este estudio, el almidón de yuca demostró ser más susceptible al ataque con la amilasa ensayada y tuvo una concentración de azúcares reductores menores que el obtenido por otros autores. Por ejemplo, Hobbs (2009), en su texto, reporta concentraciones de azúcares más elevados para almidón de maíz, entonces se considera que esta producción de azúcares reductores podría deberse a que las condiciones de operación no fueron las óptimas.

Los resultados de la determinación de la concentración de azúcares reductores obtenidos, resumidos en la Figura 5, nos muestran que, el comportamiento del almidón de yuca (Manihot esculenta) fue mejor que los otros dos almidones, obteniéndose una mayor concentración de azúcares. En cambio, para la papa (Solanum tuberosum), la concentración resultó ser muy baja; y para el camote (lpomoea batatas), el valor fue un poco más elevado, esto debido a que la constitución estructural del almidón se degrada en glucosa.

Para el almidón de yuca en el presente trabajo de investigación, la concentración de azúcares reductores encontrados en promedio es aún bajo respecto a los valores publicados por Pardo et al. (2004), quienes obtuvieron concentraciones más elevadas. Esto puede ser debido a que las condiciones de operación no fueron las más óptimas.

La principal razón por la que se obtuvo los mejores resultados con el almidón de yuca (Manihot esculenta) es debido a su menor contenido de amilosa respecto a los almidones de camote (lpomoea batatas) y papa (Solanum tuberosum). Gracias a su forma lineal y espiralada se hace más difícil la hidrólisis (Gallant, Bouchet y Baldwin, 1997).

El resultado obtenido en esta investigación concuerda con lo observado por otros investigadores, quienes demostraron que el almidón de yuca tiene susceptibilidad hacia las enzimas relativamente más altas que la de otros almidones como el camote y papa. Respecto al almidón de papa y camote, su menor producción de azúcares reductores coincide con los resultados obtenidos por López, Santacruz, Muñoz, Castillo, Córdova y Vaquera (2005) y Shariffa, Karim, Fazilah \& Zaidul (2009), quienes demostraron que el almidón de camote muestra una mayor resistencia a la alfa amilasa y al ataque de la glucoamilasa. 
Cálculo de la $\mathrm{v}_{\mathrm{o}}$ de la reacción enzimática $\mathrm{y}$ valores de Km y Vmax de los diferentes sustratos de almidón

El comportamiento de la cinética se ajustó al modelo de la ecuación de Michaelis-Menten y Linewever-Burk. Al aumentar la concentración de sustrato $\left(\mathrm{S}_{\mathrm{o}}\right)$, la velocidad de formación de producto $\left(\mathrm{v}_{\mathrm{o}}\right)$ se incrementó hasta hacerse independiente.

Como las concentraciones no fueron muy altas, la enzima no se saturó por la cantidad de almidón presente en el medio; en ese sentido, la velocidad de reacción se mantuvo estable, $\mathrm{y}_{\mathrm{o}}$ se encuentra en su máximo, tal como Rawn (1989) y otros autores afirmaron en sus recopilaciones. Esta velocidad se encuentra a concentraciones de $1 \%$ y $3 \% \mathrm{p} / \mathrm{v}$, logrando establecer una óptima concentración inicial de sustrato.

Siendo la constante de Michaelis una medida inversa a la afinidad de una enzima por el sustrato, implicaría que cuanto más pequeño sea el valor de la Km, más alta será la afinidad que se tiene por el sustrato, es decir, el complejo enzima sustrato (ES) es muy fuerte y difícilmente se disocia sin llevarse a cabo la transformación. Por lo tanto, al observar los resultados se tiene que el valor de la Km para el almidón de camote fue menor que el de la papa y la yuca. Esto permite suponer que la enzima amilasa de la bacteria termófila Bacillus licheniformis BA-3 tiene una mayor afinidad, ya que logra interactuar con gran parte del sustrato, lo cual no sucede con el almidón de yuca y papa, debido a que la enzima no alcanza a realizar catálisis al no estar en contacto con el sustrato.

\section{Identificación de la bacteria termófila BA-3}

La identificación fue realizada por el secuenciamiento del gen ARNr $16 \mathrm{~S}$ de la bacteria termófila, la misma que al ser comparada con secuencias de la base de datos del National Center of Biotechnology Information (NCBI) a través del BLAST N, resultó con un $99 \%$ de identidad con Bacillus licheniformis. Dicha bacteria es muy buena productora de amilasa termoestable (Monteiro \& Oliveira, 2010; Naidu \& Saranraj, 2013; Pandey, Nigam, Soccol, Soccol, Singh \& Mohan, 2000).

\section{CONCLUSIONES}

El rendimiento de la extracción depende de la materia seca y del contenido de almidón del tubérculo, por tanto, el mayor rendimiento se obtuvo con Solanum tuberosum (32.73\%), seguido por Manihot esculenta $(29.50 \%)$ e lpomoea batatas (21.66 \%). A nivel de laboratorio, este resultado es considerado alto y muy rentable.

La afinidad que existe entre la enzima y el sustrato se determinó de acuerdo al valor del $\mathrm{Km}$, encontrándose para almidón de Solanum tuberosum un valor de $0.4225 \mathrm{~g} / \mathrm{ml}$; para almidón de Manihot esculenta, $0.1263 \mathrm{~g} / \mathrm{ml} ;$ y $0.0024 \mathrm{~g} / \mathrm{ml}$ para el almidón de lpomoea batatas.

El valor de la $\mathrm{Km}$ más bajo obtenido $(0.0024 \mathrm{~g} / \mathrm{ml})$ por la acción de la enzima amilasa de Bacillus licheniformis BA-3 indica que dicha enzima tiene una mayor afinidad por el almidón de camote (lpomoea batatas).

\section{AGRADECIMIENTO}

Los autores expresamos nuestro agradecimiento a CONCYTEC-FINCYT por el financiamiento brindado, del mismo modo al Responsable del Laboratorio de Bioquímica de la Universidad Nacional Jorge Basadre Grohmann-Tacna, por brindarnos sus instalaciones para la ejecución de esta investigación.

\section{REFERENCIAS BIBLIOGRÁFICAS}

AOAC. (1990). Official methods of analysis. Association of Official Agricultural Chemists Washington, DC.

Aquino, A., Jorge, J., Terenzi, H. \& Polizeli, M. (2003). Studies on a thermostable aamylase from the thermophilic fungus Scytalidium thermophilum. Appl. Microbiol. Biotechnol.61(4), 323-328.

Arzapalo, D., Huamán, K., Quispe, M. y Espinoza, C. (2015). Extracción y caracterización del almidón de tres variedades de quinua (Chenopodium quinoa Willd) negra collana, pasankalla roja y blanca junín. Revista de la Sociedad Química del Perú, $18(1)$. R e c u p e r a d o d e http://www.scielo.org.pe/scielo.php?s cript $=$ sci arttext\&pid $=$ S 1810 634X2015000100006

Burhan, A., Nisa, U., Gokhan, C., Omer, C., Ashabil, A. \& Osman, G. (2003). Enzymatic properties of a novel thermostable, thermophilic, alkaline and chelator resistant amylase from an alkaliphilic Bacillus sp. isolate ANT-6. Process Biochem., 38, 1397-1403. 
Carver, W. (1937). How the farmer can save his sweet potatoes. Alabama: Institute Press.

Gallant, D., Bouchet, B. y Baldwin, P. (1997). Microscopy of Starch: Evidence of a New Level of Granule Organization. Carbohydrate Polymers, 32 (3-4), 177191 . R e c u p e r a d o d e https://www.sciencedirect.com/scienc e/article/pii/S0144861797000088

Guizar, A. (2009). Obtención y caracterización física y química del almidón de camote de cerro. (tesis de maestría). Instituto Politécnico Nacional de Michoacán, México.

Hendriksen, V., Pedersen, S. \& Bisgard-Frantzen, H. (1999). A process for textile warp sizing using enzymatically modified starches. Patent Application, WO 99/35325.

Hobbs, L. (2009) Sweeteners from starch: Production, properties and uses. Starch: Chemistry and technology.

ITINTEC. (1986). Harina de trigo para consumo doméstico y uso industrial. Tecnológica Industrial y de Normas Técnicas (ITINTEC) 205.27.

Lévêque, E., Janecek, S., Haye, B. \& Belarbi, A. (2000). Thermophilic archaeal amylolytic enzymes. Enzyme Microbiol. Technol., 26, 3-14.

López, G., Santacruz, A., Muñoz, A., Castillo, F., Córdova, L. y Vaquera, H. (2005). Caracterización morfológica de poblaciones nativas de maíz del Istmo de Tehuantepec, Oaxaca. Interciencia, 30(5), 284-290. Recuperado de http://www.redalyc.org/pdf/339/3391 0407.pdf

Monteiro, P. \& Oliveira, P. (2010). Application of microbial a-amylase in industry- A review. Brazilian Journal of Microbiology, 41(4), 850-861. $\mathrm{R} \mathrm{e} \mathrm{c} \mathrm{u} \mathrm{p} \mathrm{e} \mathrm{r} \mathrm{a} \mathrm{d} \mathrm{o} \mathrm{d} \mathrm{e}$ https://www.ncbi.nlm.nih.gov/pmc/ar ticles/PMC3769773/

Naidu, M. \& Saranraj, P. (2013). Bacterial Amylase: A Review. International Journal of Pharmaceutical \& Biological Archives, 4(2), 274-287. $\mathrm{R}$ e c u p e r a d o d e https://pdfs.semanticscholar.org/48fc/ 93d64d3b57d26214e0080c757bc616f 67238.pdf

Pandey, A., Nigam, P., Soccol, C., Soccol, V, Singh, D. \& Mohan, R. (2000). Advances in microbial amylases.
Applied Biochemistry and Biotechnology, (31), 135-152. $\mathrm{R}$ e c u p e r a d o d e https://pdfs.semanticscholar.org/79ad /7f31 ee3d1900a706b400bdca796afce 35a11.pdf

Pardo, M., Rivera, P., Castellano, O. y González, E. (2004). Estudio cinético de la hidrólisis enzimática del almidón de papa. Revista Ingeniería Investigación, 24 (1), 66-84. $\mathrm{R}$ e c u p e r a d o d e https://revistas.unal.edu.co/index.php /ingeinv/article/view/14727

Rawn, D. (1989). Bioquímica. Madrid, España: Editorial McGraw Hill.

Raygada, M. (2001). Caracterización del almidón de dos variedades de quinua (Chenopodium quinoa Willd): Kancolla y Chullpi (tesis de maestría) Universidad Nacional Agraria La Molina. Lima, Perú.

Salcedo, J., Montes, E., \& Zapata, J. (2010). Producción de jarabes de fructosa por medio de la hidrólisis enzimática del almidón de ñame. VITAE, 17(3), 243251 .

Shariffa, N., Karim, A., Fazilah, A. \& Zaidul, S. (2009). Enzymatic hydrolysis of granular native and mildly heat-treated tapioca and sweet potato starches at sub-gelatinization temperature. Food Hydrocolloids, 23(2), 434-440. Recuperado de https://pubag.nal.usd a.gov/catalog/737749

Sidhu, G.S., Sharma, P., Chakrabarti, T. \& Gupta, J.K. (1997). Strain improvement for the production of a thermostable aamylase. Enzyme and Microb. Technol., (21), 525-530.

Singh, N., Singh, J., Kaur, L., Sodhi, S. \& Gill, S. (2003). Morphological thermal and rheological properties of starches from different botanical sources A review. Food Chemistry,81(2), 219-231. Recuperado de https://eurekamag.co m/research/003/854/003854348.php

Van der Maarel, M., Van der Veen, B., Uitdehaag, J., Leemhuis, H. \& Dijkhuizen, L. (2002). Properties and applications of starch-converting enzymes of the aamylase family. J. Biotechnol., 94, 137-155.

Zajac, P. (1989). Almidón de maíz, obtención y utilización. Cuba: Editorial Científico, Técnica. 